Instructions for authors, subscriptions and further details:

\title{
Ante la Diversidad: ¿Qué Opinan y Sienten los Adolescentes? La Alteridad y la Interculturalidad a Examen
}

Paquita Sanvicén-Torné ${ }^{2}$

Conxa Fuentes Moreno ${ }^{2}$

Fidel Molina-Luque ${ }^{1}$

1) University of Lleida, Spain

2) University of Barcelona, Spain

Date of publication: February $25^{\text {th }}, 2017$

Edition period: February 2017-June 2017

To cite this article: Sanvicén-Torné, P., Fuentes Moreno, C., Molina-Luque, F. (2017). Ante la Diversidad: ¿Qué Opinan y Sienten los Adolescentes? La Alteridad y la Interculturalidad a Examen. International Journal of Sociology of Education, 6(1), 26-60. doi: 10.17583/rise.2017.2474

To link this article: http://dx.doi.org/10.17583/rise.2017.2474

PLEASE SCROLL DOWN FOR ARTICLE

The terms and conditions of use are related to the Open Journal System and to Creative Commons Attribution License (CC-BY) 


\section{Before Diversity: What do Adolescents Say and Feel? Alterity and Interculturality to Exam}

Paquita Sanvicén-Torné

University of Lleida
Conxa Fuentes Moreno

University of Barcelona
Fidel Molina-Luque

University of Lleida

(Received: 30 December 2016; Accepted: 16 January 2017; Published: 25 February 2017)

\section{Abstract}

Diversity is a structural part of all societies. Nor are those that are perceived as homogeneous. Even so, the debate on intercultural education, coexistence between groups of origins, ideologies and different thoughts has gained scientific interest from the social changes that have occurred in the population displacements of this century. Gender education has reappeared imbricated in all of this (as an urgent need). This article shows the positioning and the assessments that, based on the results of a quantitative research on a large sample of adolescents of Catalonia, say they have about alterity and differences. The variables place of birth, gender, frequency of relationships and environment have been studied. The results are statistically significant. Differences are observed in the opinions expressed according to these variables, especially between girls and boys. Although they generally express a favorable attitude to contact with the different, more of them show thoughts that reproduce traditional cultural stereotypes. Quantitative data reveal influences of educational socialization both in the classroom and in its environment. The adolescents identify the school and the neighborhood as the main spaces of social relation and place the network in third place.

Keywords: cultural diversity, adolescence, otherness, interculturality, sociology of intercultural education, identity, gender

2017 Hipatia Press

ISSN: 2014-3575

DOI: http://dx.doi.org/10.17583/rise.2017.2474
Hipatia Press

www.hipatiapress.com

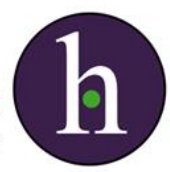




\section{Ante la Diversidad: ¿Qué Opinan y Sienten los Adolescentes? La Alteridad y la Interculturalidad a Examen}

Paquita Sanvicén Torné

University of Lleida
Conxa Fuentes Moreno

University of Barcelona
Fidel Molina Luque

University of Lleida

(Recibido: 30 Diciembre 2016; Aceptado: 16 Enero 2017; Publicado: 25 Febrero 2017)

\section{Resumen}

La diversidad forma parte estructural de todas las sociedades. Ni las que se perciben como homogéneas lo son. Aun así, el debate sobre la educación intercultural, la convivencia entre grupos de orígenes, ideologías y pensamientos distintos ha cobrado interés científico a partir de los cambios sociales acaecidos por los desplazamientos poblacionales de este siglo. Imbricado en él ha reaparecido, como urgente necesidad, la educación de género. Este artículo muestra el posicionamiento y las valoraciones que, a partir de los resultados de una investigación cuantitativa sobre una amplia muestra de adolescentes de Cataluña, dicen tener sobre la alteridad y las diferencias. Se han estudiado las variables sexo, lugar de nacimiento, frecuencia de relaciones y entorno. Los resultados son estadísticamente significativos. Se advierten diferencias en las opiniones expresadas según estas variables, especialmente entre chicas y chicos. Aunque en general manifiestan una actitud favorable al contacto con el diferente, un mayor número de ellos que ellas muestran pensamientos que reproducen los estereotipos culturales tradicionales. Los datos cuantitativos revelan influencias de la socialización educativa tanto en el aula como en su entorno. Los adolescentes identifican la escuela y el barrio como los espacios principales de relación social y sitúan la red en tercer lugar.

Palabras clave: diversidad cultural, adolescencia, alteridad, interculturalidad, sociología de la educación intercultural, identidad, género

2017 Hipatia Press

ISSN: 2014-3575

DOI: http://dx.doi.org/10.17583/rise.2017.2474
Hipatia Press

www.hipatiapress.com

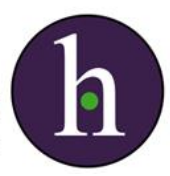




\section{Sanvicén, Fuentes \& Molina - Alteridad e Interculturalidad}

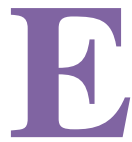

1 artículo que se presenta tiene como objeto describir los resultados del proyecto de investigación titulado "Educación cívica en las aulas interculturales: análisis de las representaciones e ideas sociales al alumnado y propuestas de acción educativa" que ha sido realizado por los grupos de investigación DHIGECS (Universidad de Barcelona) y GESEC (Universidad de Lleida) en el marco de la convocatoria de proyectos de la Obra Social la Caixa, RecerCaixa (2012 ACUP00185). ${ }^{1}$

Los tres grandes objetivos del proyecto están en relación con ámbitos referidos a la sociología aplicada y la educación cívica, política e intercultural. Los objetivos que se persiguen son los siguientes:

1. Describir y analizar las percepciones y valoraciones del alumnado de Educación Secundaria Obligatoria de Cataluña sobre la convivencia intercultural y la participación ciudadana en sociedades plurales y diversas.

2. Identificar y describir los conocimientos y representaciones sobre el sistema político de los adolescentes catalanes, teniendo en cuenta sus perfiles socioeconómicos y culturales.

3. Identificar y canalizar el grado de implicación de jóvenes adolescentes de diversos orígenes culturales y nacionales en las diversas formas de participación ciudadana existentes, tanto en el ámbito escolar como en los ambientes juveniles (ocio, clubes deportivos...)

Para alcanzar estos objetivos se diseñó un instrumento metodológico complejo, basado en un cuestionario sociológico, una prueba de conocimientos y una propuesta de entrevista semiestructurada a muestras de profesores y alumnos.

La técnica del cuestionario y la prueba de conocimientos se aplicaron a 27 centros escolares públicos y concertados, rurales y urbanos, llegándose a aplicar a una muestra de 1709 escolares catalanes.

De entre todos los aspectos que se tratan en dicha investigación, en el presente artículo nos interesa especialmente indagar sobre las representaciones e ideas sociales del alumnado de Educación Secundaria Obligatoria en las aulas interculturales. Concretamente, el eje temático 
conductor será reflexionar sobre las percepciones y valoraciones de los estudiantes analizados sobre la alteridad y la convivencia intercultural, teniendo en cuenta las variables de género y lugar de nacimiento. Sobre la diferencia de género y la convivencia con personas de orígenes, creencias o conductas diferentes a ellos, las preguntas-guía que nos planteamos responder en este contexto heterogéneo son, ¿Cuál es su actitud? ¿Hay diferencias entre haber nacido en Catalunya, en el resto de España o fuera? ¿Hay diferencias de actitud según el sexo, el entorno familiar y grupal? Igualmente nos preguntamos, ¿qué papel juega Internet en el entorno digital actual donde se perfila como un potente agente de influencia socializadora?

\section{Metodología}

De entre todos los instrumentos metodológicos diseñados y, por la propia naturaleza del objeto de estudio que se analiza en este artículo, nos centramos en la descripción y análisis del cuestionario sociológico. Los aspectos temáticos y su distribución quedan especificados en la tabla 1 . 


\section{Sanvicén, Fuentes \& Molina-Alteridad e Interculturalidad}

Tabla 1.

Esquema del contenido del cuestionario

\begin{tabular}{|c|c|}
\hline Contenido: Tema & Preguntas \\
\hline $\begin{array}{l}\text { Contexto } \\
\text { sociodemográfico y } \\
\text { lenguas vehiculares }\end{array}$ & $\begin{array}{l}\text { - Sexo. } \\
\text { - Lugar de nacimiento. } \\
\text { - Estudios. } \\
\text { - Actividad laboral. } \\
\text { - } \text { Religión. } \\
\text { - } \text { Capital cultural de la familia. } \\
\text { - Uso de internet. } \\
\text { - } \quad \text { Lenguas vehiculares. }\end{array}$ \\
\hline $\begin{array}{l}\text { Identidad y aceptación } \\
\text { de la multiculturalidad }\end{array}$ & $\begin{array}{l}\text { - Sentimiento nacional: Cataluña y España } \\
\text { - Sentimiento de pertenencia: barrio, pueblo, ciudad, país, } \\
\text { Europa... } \\
\text { - Inmigración y derechos políticos. } \\
\text { - Relaciones con los compañeros recién llegados. } \\
\text { - Estereotipos sobre los recién llegados. } \\
\text { - } \text { Convivencia en los centros escolares }\end{array}$ \\
\hline $\begin{array}{l}\text { Actividades escolares y } \\
\text { extraescolares }\end{array}$ & $\begin{array}{l}\text { - Actividades extraescolares realizadas. } \\
\text { - Estrategias didácticas empleadas en las clases de Ciencias } \\
\text { Sociales. }\end{array}$ \\
\hline Actitudes políticas & $\begin{array}{l}\text { - Actitudes políticas en la familia. } \\
\text { - Participación e interés por la política. } \\
\text { - Partidos políticos. } \\
\text { - España y Cataluña } \\
\text { - Unión europea. } \\
\text { - Democracia. } \\
\text { - Satisfacción por el sistema democrático y los partidos. } \\
\text { - Religión y estado. }\end{array}$ \\
\hline Roles de género & - Actitudes sexistas \\
\hline $\begin{array}{l}\text { Medios de } \\
\text { comunicación }\end{array}$ & - Medios de comunicación e información política \\
\hline
\end{tabular}

El trabajo de campo del estudio se realizó en Cataluña durante el 2014. Se aplicaron cuestionarios y entrevistas semiestructuradas a alumnado de $4^{\circ}$ de la ESO, en su mayoría con 16 años edad. El cuestionario, con 103 preguntas y 616 ítems en total, estaba dividido en tres partes: un cuestionario sociológico, uno de opinión y una prueba de conocimiento. Algunas de las preguntas de los cuestionarios fueron de elaboración propia, consensuadas entre los investigadores del proyecto en diversas reuniones. Otras preguntas 
fueron adaptadas de diferentes estudios previos, a fin de asegurar la fiabilidad de las mismas y la posibilidad de realizar estudios comparativos.

Estas pruebas fueron aplicadas a 1709 alumnos de 30 centros de secundaria de toda Cataluña. El tamaño de la muestra se calculó teniendo en cuenta como universo la totalidad del alumnado de Educación Secundaria Obligatoria de Cataluña, 285.461 sujetos según datos oficiales del 2013 (Generalitat de Catalunya, 2013). La muestra recomendada para un estudio al $99 \%$ de Nivel de Confianza y un margen de error del $3 \%$ era de 1.832 sujetos. Si hubiéramos optado por tener en cuenta sólo el alumnado de $4^{\circ}$ de la ESO, unos 72.000 alumnos aproximadamente -no existen datos oficiales, pero se puede obtener una aproximación si dividimos el total de alumnado que cursaba ESO por el número de cursos que dura este ciclo- la muestra debería de haber sido de 1798 sujetos. La muestra final alcanzada, 1.709 sujetos, resulta todo un éxito si tenemos en cuenta que la muestra recomendada, teniendo en cuenta la totalidad de alumnado de ESO del curso 2014 (Generalitat de Catalunya, 2014), al 99\% NC y 5\% de margen de error, sería de 662 individuos. La selección de los sujetos de la muestra vehiculó a través de la selección de los centros educativos, elegidos por su características en función de criterios definidos por el equipo de investigación y conveniencia, configurando una muestra no probabilística, en tanto que no aleatoria, de segmentos identificables (Grande \& Abascal, 2009).

Se logró respetar el porcentaje relativo de centros públicos y privadosconcertados sobre el total de la muestra, en una relación del $63 \%$ de públicos sobre el $37 \%$ de privados-concertado, teniendo en la muestra 19 públicos y 11 centros privados-concertados. El 24,4\% de los centros de la muestra tenía menos del $10 \%$ de sujetos nacidos fuera de España; el 27,9\% entre el 10 y el $20 \%$, el $34.2 \%$ entre un $20 \%$ y un $40 \%$ y un $13.6 \%$ de los centros de la muestra tenían más del $40 \%$ de sujetos nacidos fuera de España.

En definitiva, el estudio al cual corresponde este artículo se ha realizado mayoritariamente en centros públicos, hecho que implica que los estudiantes forman parte de aulas y espacios educativos formales con un alto grado de diversidad cultural. En ese contexto la investigación pretendía conocer cuál es su actitud frente al trato, la colaboración, diálogo y valoración de las personas que no reconocen que son, piensan o actúan como ellos. Hemos analizado estos resultados en función del sexo y el lugar de nacimiento ya 


\section{Sanvicén, Fuentes \& Molina - Alteridad e Interculturalidad}

que son las dos variables significativas que incorporan por ellas mismas los elementos básicos de la alteridad: género, diferencias culturales, religiosas, etc.

\section{El Perfil de los Adolescentes Estudiados}

De los 1.709 alumnos a los que se ha pasado la encuesta, $51 \%$ son chicos y el $48,4 \%$ chicas. (Tabla 2 ). De los chicos, el 53'3\% ha nacido en Cataluña, el 31'3 procede del resto de España y el restante $46 \% 6 \%$ del extranjero. La mayoría de las chicas, un 54\% no han nacido aquí. De ellas, un 68'8\% lo hicieron en el resto de estado español, y el 52\% $\%$ fuera de España. Se da la circunstancia que ningún alumno que manifiesta haber nacido "en el resto de España" ha indicado cuantos años tenía cuando llegó a Cataluña. En cambio, sí que lo han indicado los nacidos fuera.

Tabla 2

Muestra por sexo y lugar de origen (absolutos y porcentajes)

\begin{tabular}{|c|c|c|c|c|c|c|}
\hline \multicolumn{3}{|l|}{ Sexo } & \multicolumn{3}{|c|}{ Lugar de nacimiento } & \multirow[b]{2}{*}{$\mathrm{Ns} / \mathrm{nc}$} \\
\hline Chico & Chica & $\mathrm{Ns} / \mathrm{nc}$ & Cataluña & Resto España & $\begin{array}{l}\text { Fuera } \\
\text { España }\end{array}$ & \\
\hline $\begin{array}{l}878 \\
(51,3 \%)\end{array}$ & $\begin{array}{l}828 \\
\left(48^{\prime} 4 \%\right)\end{array}$ & $\begin{array}{l}3 \\
(1,7 \%)\end{array}$ & $\begin{array}{l}1305 \\
\left(76^{\prime} 4 \%\right)\end{array}$ & $\begin{array}{l}32 \\
\left(1{ }^{\prime} 9 \%\right)\end{array}$ & $\begin{array}{l}369 \\
\left(21^{\prime} 6 \%\right)\end{array}$ & $\begin{array}{l}2 \\
(0,5)\end{array}$ \\
\hline Total & & & Total & & & \\
\hline
\end{tabular}

Como se detalla en la Tabla 3, se comprueba que el 30,6 de los nacidos en el extranjero tenían más de ocho cuando llegaron a Cataluña; sumados a los que tenían más de 6 años, corresponden al 56\% del total. Son edades con la que ya tienen vivencias de socialización, conciencia y memoria de ellas. Más relevante, en ese caso, es el hecho que han venido aquí con sus progenitores o familiares, por tanto su núcleo de socialización (lingüística, religiosa, normativa...) en el hogar en Cataluña es de origen no autóctono hecho que implica costumbres, normas, lenguas y unas experiencias vivenciales propias, que les aportan, como se verá en los apartados siguientes, elementos diferenciales respecto al resto. 
Tabla 3

Edad de los estudiantes nacidos fuera de España al llegar a Cataluña

\begin{tabular}{ll}
\hline Edad al llegar a Cataluña & Nacidos fuera de España \\
\hline Menos de 2 años & 7,0 \\
Entre 2 y 5 años & 33,9 \\
Entre 6 y 8 años & 26,0 \\
Más de 8 años & 30,6 \\
Ns/nc & 2,4 \\
\hline
\end{tabular}

\section{La Alteridad Valorada por los y las Adolescentes}

Es un hecho ampliamente estudiado por la sociología que la existencia de un alto grado de diversidad poblacional en un espacio geográfico no implica, si no se llevan a cabo estrategias educativas y sociales, un mayor contacto ni interrelación ni comprensión entre grupos ni valoración de la diferencia como valor. (Alcoverro, 2005; Deusdad, 2009; Esquirol, 2005; Garreta, 2004; Jorba, 2011; Villalobos et alter, 2016)

A partir del análisis de las preguntas de escala se les pidió que manifestaran el grado de acuerdo con una serie de afirmaciones dadas del bloque $18 .^{2}$

Tabla 4

Bloque 18

Bloque 18. Alteridad

Marca la casilla de cada fila que mejor se ajuste a tu opinión: Totalmente en desacuerdo; en desacuerdo; ni de acuerdo ni en desacuerdo; de acuerdo; totalmente de acuerdo

- Me gusta trabajar en grupo o en proyectos con personas de realidades y experiencias diferentes a las mías.

- Creo que es importante escuchar las ideas de los otros, incluso si son muy diferentes a las mías.

- Creo interesante hablar con gente que tiene creencias religiosas diferentes a las mías.

- Me gusta hablar con personas con puntos de vista políticos diferentes a los míos.

- Puedo aprender mucho de las personas que tienen realidades y experiencias diferentes de las mías. 


\section{Sanvicén, Fuentes \& Molina-Alteridad e Interculturalidad}

Para facilitar la lectura de los datos, se han diferenciado en dos apartados los referidos a la valoración de la diferencia y los referidos a las actitudes y opiniones respecto a los roles de género. Así, el primero recoge los aspectos referidos al grado de interés por interactuar con personas de diferentes realidades, orígenes y experiencias, dialogar con ellas y escuchar sus opiniones. También se les preguntó sobre si creen que pueden aprender de ellas (Tablas 5, 6, 7, 8 y 9). El segundo apartado analiza las valoraciones dadas en las afirmaciones sobre roles tradicionalmente atribuidos al hombre y la mujer (Tablas 10, 11, 12, 13 y 14).

\section{Actitudes respecto la interacción con personas que no son ni piensan como yo}

Sobre la afirmación "Me gusta trabajar en grupos o en proyectos con personas o realidades y experiencias diferentes de las mías", los datos obtenidos muestran su interés por el volumen de cifras con significación estadística que se han obtenido. Tal como queda recogido en la Tabla 5, el primer dato relevante es que aunque el grado más alto de respuestas, 38,4\% están en el De acuerdo (en cifras absolutas corresponde a unos 656 estudiantes), un porcentaje de respuestas similar se concentran en la posición $\mathrm{Ni}$ de acuerdo, ni en desacuerdo. El 34,9\%, (correspondiente en números absolutos a 596 estudiantes) se sitúa en este ítem de ambigüedad: ni a favor ni en contra. Resaltamos este dato ya que de las preguntas analizadas ésta es la que presenta un porcentaje más alto de respuestas centradas en ese espacio intermedio, junto con la afirmación referente a las creencias religiosas de los demás (véase Tabla 8).

A su vez, analizados a partir de la variable sexo, todos los resultados obtenidos son significativos. Respecto al porcentaje global del ambiguo "ni de acuerdo, ni en desacuerdo" ya comentado, los hombres se sitúan por encima de él, en un significativo $37,9 \%$ y las mujeres se sitúan también significativamente por debajo en un $31,6 \%$. La diferencia entre unos y otros que supera los 6 puntos porcentuales es relevante. 
Tabla 5

Me gusta trabajar en grupos o en proyectos con personas o realidades $y$ experiencias diferentes de las mías. Variable sexo y lugar de nacimiento. \%

\begin{tabular}{|c|c|c|c|c|c|c|}
\hline Respuesta & Total & Chico & Chica & Cataluña & $\begin{array}{l}\text { Resto } \\
\text { España }\end{array}$ & $\begin{array}{l}\text { Fuera } \\
\text { España }\end{array}$ \\
\hline $\begin{array}{l}\text { Totalmente en } \\
\text { desacuerdo }\end{array}$ & 4,2 & $5,9+$ & $2,1-$ & 3,8 & - & 5,4 \\
\hline En desacuerdo & 6,6 & $8,1+$ & $5,0-$ & 6,5 & 9,4 & 6,5 \\
\hline $\begin{array}{l}\text { Ni de acuerdo, ni en } \\
\text { desacuerdo }\end{array}$ & 34,9 & $37,9+$ & $311^{\prime} 6-$ & 36,1 & 21,9 & 31,7 \\
\hline De acuerdo & 38,4 & $34,3-$ & $42,9+$ & 38,8 & 46,9 & 36,3 \\
\hline $\begin{array}{l}\text { Totalmente de } \\
\text { acuerdo }\end{array}$ & 14,3 & $11,6-$ & $17,3+$ & $13,1-$ & 21,9 & $18,2+$ \\
\hline $\mathrm{Ns} / \mathrm{Nc}$ & 1,7 & 2,2 & 1,2 & 1,7 & - & 1,9 \\
\hline
\end{tabular}

Por otro lado, el 60,2\% de las mujeres ha concentrado la mayoría de sus respuestas en los dos ítems con más alto grado de acuerdo de la escala (de acuerdo/totalmente de acuerdo). En el caso de los hombres, la suma de los dos ítems es solo del 45,9\%. Es interesante reseñar otras diferencias significativas entre las respuestas de ellas y ellos. Por un lado se observa que hay una diferencia de 3,8 puntos porcentuales en estar en total desacuerdo con la afirmación. Sumados a estos datos los que corresponden al desacuerdo sin matices, también estadísticamente significativos, la diferencia aumenta hasta los 7 puntos.

Considerando los resultados teniendo en cuenta el lugar de nacimiento de los adolescentes, se observa que el porcentaje de acuerdo mayoritario lo alcanza significativamente el grupo de los nacidos fuera de España, 18,2\% (+). Igual de interesante es observar que el menor porcentaje en ese nivel es el que corresponde a los nacidos en Cataluña con un $13,1 \%$ cinco y siete puntos porcentuales del resto de grupos. 


\section{Sanvicén, Fuentes \& Molina - Alteridad e Interculturalidad}

Tabla 6

Puedo aprender mucho de las personas que tienen realidades y experiencias diferentes de las mías. Variable sexo y lugar de nacimiento. \%

\begin{tabular}{|c|c|c|c|c|c|c|}
\hline Respuesta & Total & Chico & Chica & Cataluña & $\begin{array}{c}\text { Resto } \\
\text { España }\end{array}$ & $\begin{array}{l}\text { Fuera } \\
\text { España }\end{array}$ \\
\hline $\begin{array}{l}\text { Totalmente } \\
\text { desacuerdo }\end{array}$ & 0.9 & 1.3 & 0.6 & 0.8 & - & 1.1 \\
\hline En desacuerdo & 2.3 & 2.7 & 1.9 & 2.1 & 3.1 & 14.9 \\
\hline $\begin{array}{l}\mathrm{Ni} \text { de acuerdo, ni en } \\
\text { desacuerdo }\end{array}$ & 13.2 & $16.2+$ & $9.8-$ & $48.3+$ & 40.6 & $42.3-$ \\
\hline De acuerdo & 46.8 & 45.3 & 48.6 & 34.2 & 40.6 & 42.3 \\
\hline Totalmente de acuerdo & 34.8 & $32.0-$ & $37.8+$ & 34.2 & 40.6 & 36.6 \\
\hline $\mathrm{Ns} / \mathrm{Nc}$ & 1.9 & 2.5 & 1.3 & 2.0 & - & 1.9 \\
\hline
\end{tabular}

Las cifras aumentan significativamente cuando responden por el grado de percepción que tienen sobre las enseñanzas de los demás. En el caso de las chicas, las cifras pasan del 17,3\% del "trabajar con" anterior al 37,8\% "aprender de" actual. Igualmente en los chicos el aumento es más de veinte puntos pasando del $11,6 \%$ al $32,0 \%$. Igual comportamiento en las respuestas se observa según la variable de origen, que aumentan igualmente en general sobre los veinte puntos porcentuales en todos los casos.

Cuando se analiza las respuestas relativas a la actitud respecto a la escucha activa (creo que es importante escuchar las ideas de los otros, incluso si son muy diferentes a las mías), los datos reflejan diferencias poco significativas con el conjunto. Se mantienen significativos los resultados diferenciales entre sexos. A su vez, continúa destacando la ausencia total de desacuerdo en los españoles nacidos fuera de Cataluña que en esta pregunta es total, sin matices. En el caso de los grupos según origen, cabe resaltar la significación estadística de los nacidos en Cataluña y en el extranjero en las posiciones intermedias de la escala. A destacar el 5,1\% de los que creen que escuchar las ideas diferentes de los demás es importante, que supera los resultados del resto de grupos y el 40,9\% de los que están de acuerdo con esa idea, la cifra más baja del resto. Con todo es relevante señalar que todos los grupos, por sexo y por origen, se sitúan entre el $40 \%$ y el $50 \%$ en la opción "de acuerdo" y solo entre un $32 \%$ y $33 \%$ se manifiestan totalmente de acuerdo. 
Tabla 7

Creo que es importante escuchar las ideas de los otros, hasta si son muy diferentes a las mías. Variable sexo y lugar de nacimiento. \%

\begin{tabular}{llllllc}
\hline Respuesta & Total & Chico & Chica & Cataluña & $\begin{array}{c}\text { Resto } \\
\text { España }\end{array}$ & $\begin{array}{l}\text { Fuera } \\
\text { España }\end{array}$ \\
\hline $\begin{array}{l}\text { Totalmente en } \\
\text { desacuerdo }\end{array}$ & 1,2 & 1,5 & 1 & 1.1 & - & 1,6 \\
$\begin{array}{l}\text { En desacuerdo } \\
\text { Ni de acuerdo, ni en }\end{array}$ & 2,9 & $3,6+$ & $1,8-$ & $2,3-$ & - & $5,1+$ \\
desacuerdo & 13,5 & $16,1+$ & $10,9-$ & $12,3-$ & 21,9 & $17,1+$ \\
$\begin{array}{l}\text { De acuerdo } \\
\text { Totalmente de }\end{array}$ & 47,9 & 48,2 & 47,7 & $50,0+$ & 43,8 & $40,9-$ \\
$\begin{array}{l}\text { acuerdo } \\
\text { Ns/Nc }\end{array}$ & 32,8 & $28,4-$ & $37,6+$ & 32,6 & 34,4 & 33,3 \\
\hline
\end{tabular}

Es sabido que uno de los aspectos socialmente más complejos en la relación entre las culturas es sin duda la religión. La población que ha llegado a España y Cataluña a lo largo de este siglo ha puesto en evidencia la heterogeneidad religiosa preexistente invisibilizada por la presencia absoluta de la religión católica aun hegemónica. (Estruch, 2001, 2007; Generalitat de Catalunya, 2014b)

Previamente se había preguntado a los estudiantes como se autodefinían, en una pregunta de respuesta única (pregunta Bloque 1. Pregunta $9^{3}$ ) La tabla 6 muestra que, en general, no llega al $40 \%$ los adolescentes que se manifiestan agnósticos. El 21,6\% dicen ser creyentes aun sin especificar el tipo de creencia. Del resto que sí que lo especifican, el 16,6\% se manifiesta católico mientras que un $7,3 \%$ el Islam. Aun así, se observa que la musulmana es la religión mayoritaria de los nacidos fuera de España, con un significativo $22,8 \%$. Igualmente cabe destacar los porcentajes superiores al $6 \%$ en cada caso de protestantes y ortodoxos, religiones que permanecen invisibles para el conjunto de la sociedad. Interesante observar que en todas las religiones las cifras de chicas creyentes superan las de los chicos. Respecto al catolicismo, es igualmente relevante observar que el número de las que se manifiestan como seguidoras superan ampliamente el de seguidores. 
Tabla 8

Autoidentificación religiosa. Variables sexo y lugar de nacimiento. (\%)

\begin{tabular}{lcccccc}
\hline Respuesta & Total & Chico & Chica & Cataluña & $\begin{array}{c}\text { Resto } \\
\text { España }\end{array}$ & $\begin{array}{c}\text { Fuera } \\
\text { España }\end{array}$ \\
\hline $\begin{array}{l}\text { No creo en } \\
\text { ningún dios }\end{array}$ & 39,1 & $42,3+$ & $36,0-$ & $46,7+$ & 40,6 & $12,7-$ \\
$\begin{array}{l}\text { Creo en } \\
\text { dios/Dirigente }\end{array}$ & 21,6 & 22,1 & 21,1 & 21,8 & 28,1 & 20,3 \\
$\begin{array}{l}\text { religión } \\
\text { Rel. católica }\end{array}$ & 16,6 & $13,3-$ & $20,2+$ & 16,2 & 12,5 & 18,4 \\
Rel. musulmana & 7,3 & 6,9 & 7,4 & $2,9-$ & 6,3 & $22,8+$ \\
Rel. & 2,9 & 2,8 & 3,0 & $1,8-$ & 6,3 & $6,8+$ \\
$\begin{array}{l}\text { Protes./evang } \\
\text { Rel. Ortodoxa }\end{array}$ & 2,2 & 1,6 & 2,9 & $1,1-$ & - & $6,2+$ \\
Rel. Budista & 1,2 & 1,1 & 1,2 & 1,0 & - & 1,9 \\
$\begin{array}{l}\text { Rel. Judía } \\
\text { Otros }\end{array}$ & 0,1 & - & 0,2 & 0,1 & - & 0,3 \\
Ns/nc & 8,0 & 8,5 & 7,4 & 7,7 & 3,1 & 9,5 \\
\hline
\end{tabular}

Cuando se les pregunta por su interés en entablar diálogo con los que profesan otras religiones, se observa una cierta actitud de refracción (Tabla 9. Bloque 18. Pregunta 1 Encuentro interesante hablar con la gente que tiene creencias religiosas diferentes de las mías. ). Sobre los resultados globales se observa que una cantidad importante, que supera el $30 \%$ se mantiene en la posición ambigua. Sumados los dos ítems de mayor acuerdo en la escala alcanzan el 48,7\%; con lo cual se evidencia que más del $50 \%$ se posiciona entre el "ni si, ni no" y el no rotundo que alcanza el 16,1\%. En ese sentido, cabe señalar el alto porcentaje de los nacidos en el resto de España que se manifiestan en la posición ambigua $(53,1 \%)$, veinte puntos por encima del resultado del resto de grupos por origen.

Analizados al detalle, vemos como significativos estadísticamente los índices de acuerdo con el interés del dialogo más altos en las chicas que en los chicos. A la vez, esta proporción se invierte en el caso de la opción ambigua del "ni de acuerdo, ni en desacuerdo." Más relevante aun es que un $10,5 \%$ de chicos está totalmente en desacuerdo con el hecho que dialogar con creyentes de otras religiones tenga interés. El porcentaje de las chicas no llega al $6 \%$. 
Tabla 9

Encuentro interesante hablar con la gente que tiene creencias religiosas diferentes de las mías. Variables sexo y lugar de nacimiento. (\%)

\begin{tabular}{|c|c|c|c|c|c|c|}
\hline Respuesta & Total & Chico & Chica & Cataluña & $\begin{array}{l}\text { Resto } \\
\text { España }\end{array}$ & $\begin{array}{l}\text { Fuera } \\
\text { España }\end{array}$ \\
\hline $\begin{array}{l}\text { Totalmente en } \\
\text { desacuerdo }\end{array}$ & 8,3 & $10.5+$ & $5,9-$ & 9 & 9,4 & 5,4 \\
\hline En desacuerdo & 7,8 & 8,9 & 6,6 & 8 & 6,3 & 7,3 \\
\hline $\begin{array}{l}\mathrm{Ni} \text { de acuerdo, ni } \\
\text { en desacuerdo }\end{array}$ & 33,4 & $35,6+$ & $30,9-$ & 32,6 & $53,1+$ & 34,1 \\
\hline De acuerdo & 31,2 & $27,8-$ & $34,9+$ & 32,2 & 18,8 & 29,3 \\
\hline $\begin{array}{l}\text { Totalmente de } \\
\text { acuerdo }\end{array}$ & 17,5 & $15,0-$ & $20,2-$ & $16,5-$ & 12,5 & $21,7+$ \\
\hline $\mathrm{Ns} / \mathrm{Nc}$ & 1,8 & 2,2 & 1,4 & 1,8 & - & 2,2 \\
\hline
\end{tabular}

El concepto país de origen, a la vista de los resultados, parece que genera más expectativas que la religión (Tabla 10 Bloque 18. Pregunta 1. Puedo aprender mucho de la gente que ha llegado de otros países). Aun así, según los resultados globales, solo el 60,4\% manifiesta estar de acuerdo o totalmente de acuerdo con que se puede aprender mucho de las personas llegadas de otros países. Analizados al detalle, se observa que aunque coinciden en el porcentaje de ambigüedad, una vez más ellas se manifiestan más permeables al trato con las diferencias que los chicos. En ambos casos, los márgenes diferenciales son amplios: los resultados del desacuerdo son $7,1 \%$ en las chicas y $12,6 \%$ en los chicos; en el caso de los ítems que manifiestan claramente el acuerdo son $61,0 \%$ frente al $47,2 \%$ respectivamente. 
Tabla 10

Puedo aprender mucho de la gente que ha llegado de otros países. Variable sexo y lugar de nacimiento. \%

\begin{tabular}{|c|c|c|c|c|c|c|}
\hline Respuesta & Total & Chico & Chica & Cataluña & $\begin{array}{l}\text { Resto } \\
\text { España }\end{array}$ & $\begin{array}{l}\text { Fuera } \\
\text { España }\end{array}$ \\
\hline $\begin{array}{l}\text { Totalmente en } \\
\text { desacuerdo }\end{array}$ & 4,2 & $5,1+$ & $3,1-$ & 4,2 & 9,4 & 3,5 \\
\hline En desacuerdo & 5,9 & $7,5+$ & 4- & 6,1 & 3,1 & 5,7 \\
\hline $\begin{array}{l}\text { Ni de acuerdo, ni } \\
\text { en desacuerdo }\end{array}$ & 28,4 & 28,4 & 28,4 & $29,7+$ & 34,4 & $23,0-$ \\
\hline De acuerdo & 39,5 & 39,1 & 40,1 & 40,5 & 25,0 & 37,4 \\
\hline $\begin{array}{l}\text { Totalmente de } \\
\text { acuerdo }\end{array}$ & 19,9 & 18,1 & $21,9+$ & $17,4-$ & 28,1 & $28,2+$ \\
\hline $\mathrm{Ns} / \mathrm{Nc}$ & 2,2 & 1,8 & 2,5 & 2,2 & - & 2,2 \\
\hline
\end{tabular}

Analizados los datos en función del origen de los adolescentes, se observa que el mayor porcentaje de acuerdo se concentra en los nacidos fuera de España, los cuales se sitúan en menor medida en la ambigüedad, un 23,0\% respecto al 29,7\% de los nacidos en Cataluña y el 34,4\% de los nacidos en España. Respecto a los nacidos aquí, aunque se manifiestan de acuerdo el 57,9\%, cabe destacar que de ellos solo el 17,4\% lo está totalmente. Significativamente, este resultado se sitúa muy por debajo de los resultados del resto de grupos de origen.

De manera complementaria a los datos segmentados que se acaban de analizar, es interesante observar las cifras globales en su conjunto ya que permiten radiografiar las actitudes de los adolescentes encuestados sobre los supuestos dados. Unas actitudes que reflejan a su vez contradicciones internas interesantes de reseñar. La tabla 11 representa el resumen de los resultados globales de la pregunta 1 del Bloque 18. Se han sumado los resultados parciales y se ha obtenido los tres niveles de actitud. Por un lado, como ya se ha dicho, la diversidad religiosa es la que genera menos empatía. Pero a la vez, la percepción del interés de escuchar y aprender de personas de realidades y países distintos -en los cuales en muchos casos está implícita una práctica religiosa distintiva- alcanza altos valores que van des del 59,4\% al $80,7 \%$. Por otro lado, parecer sorprendente el hecho que mientras un $80,6 \%$ manifiestan que "pueden aprender mucho de las personas que tienen realidades y experiencias diferentes" esa cifra baja significativamente más 
de treinta puntos porcentuales hasta el $52,7 \%$.

Tabla 11

Total de resultados por grados de acuerdo según la escala.

\begin{tabular}{llll}
\hline Respuesta & $\begin{array}{l}\text { Acuerdo } \\
\text { (suma } \\
\text { De } \\
\text { acuerdo+ } \\
\text { Totalmente } \\
\text { acuerdo) }\end{array}$ & $\begin{array}{l}\text { Ambigüedad } \\
\text { (Ni desacuerdo) } \\
\text { acuerdo/ ni en } \\
\text { desacuerdo }\end{array}$ & $\begin{array}{l}\text { Desama } \\
\text { (sumente } \\
\text { desacuerdo+ } \\
\text { En } \\
\text { desacuerdo) }\end{array}$ \\
\hline $\begin{array}{l}\text { Encuentro interesante hablar con la gente } \\
\text { que tiene creencias religiosas diferentes de }\end{array}$ & 48,7 & 33,4 & 15,6 \\
$\begin{array}{l}\text { las mías. } \\
\begin{array}{l}\text { Me gusta trabajar en grupos o en proyectos } \\
\text { con personas o realidades y experiencias } \\
\text { diferentes de las mías }\end{array}\end{array}$ & 52,7 & 34,9 & 10,8 \\
$\begin{array}{l}\text { Puedo aprender mucho de la gente que ha } \\
\text { llegado de otros países }\end{array}$ & 59,4 & 28,4 & 10,1 \\
$\begin{array}{l}\text { Puedo aprender mucho de las personas que } \\
\text { tienen realidades y experiencias diferentes } \\
\text { de las mías. }\end{array}$ & 80,6 & 13,2 & 3,2 \\
$\begin{array}{l}\text { Creo que es importante escuchar las ideas de } \\
\text { los otros, hasta si son muy diferentes a las } \\
\text { mías }\end{array}$ & 80,7 & 13,5 & 4,1 \\
\hline
\end{tabular}

La hipótesis explicativa que manejamos tiene que ver por un lado con la cerrazón de los grupos religiosos en sí mismos y la falta de una educación cívica y comprensiva sobre las religiones en plural, no solo en las escuelas sino en las ciudades. A ello se añade, desde nuestro punto de vista, la distancia entre la manifestación teórica y la práctica en relación con los espacios de socialización y las experiencias vividas, o no, en las aulas en la formación de grupos de trabajo y estudio. Con todo, cabe valorar como una oportunidad -que debería manifestarse en actividades de aula favorecedoras del conocimiento mutuo efectivo- que más del 80 por ciento del total se manifiesta favorable a ello.

\section{Actitudes respecto a la diferencia de género}

Igualmente, a partir de preguntas de escala, se ha preguntado a los adolescentes el grado de acuerdo con afirmaciones sobre toma de decisiones en situaciones cotidianas en que la visión de género es determinante. 


\section{Sanvicén, Fuentes \& Molina-Alteridad e Interculturalidad}

Tabla 12

Bloque 20

Bloque 20 Roles de género

En este apartado te planteamos algunas frases y preguntas sobre chicos y chicas, hombres y mujeres y el rol que deberían tener, en tu opinión, en nuestra sociedad.

Marca la casilla de cada fila que mejor se ajuste a tu opinión: Totalmente en desacuerdo; en desacuerdo; ni de acuerdo ni en desacuerdo; de acuerdo; totalmente de acuerdo

Frases:

-Si en casa tanto el hombre como la mujer trabajan fuera, el hombre debería participar en las labores domésticas como fregar los platos o lavar la ropa.

-No pasa nada si una chica quiere practicar deportes bruscos como el rugby o el boxeo.

-En una familia numerosa, de debería incitar más a los chicos que a las chicas que vayan a la universidad.

- En general el padre debería tener más autoridad que la madre a la hora de tomar las decisiones que afecten a la familia.

- No pasa nada si una chica le pide para salir a un chico

- Es más importante que los chicos tengan éxito en el colegio que las chicas.

- Si un chico no quiere salir de fiesta, su pareja debería quedarse en casa también.

-Si una chica no quiere salir de fiesta, su pareja debería quedarse en casa también.

- Las chicas deberían de preocuparse más de llegar a ser buenas esposas y madres, en lugar de preocuparse en querer tener una profesión bien considerada.

Como en el apartado anterior, también se observa diferencias altamente significativas. 


\section{Tabla 13}

Si en una casa tanto el hombre como la mujer trabajan fuera de casa, el hombre debería participar en las tareas del hogar. Variable sexo y lugar de nacimiento (\%)

\begin{tabular}{lllllll}
\hline Respuesta & Total & Chico & Chica & Cataluña & $\begin{array}{c}\text { Resto } \\
\text { España }\end{array}$ & $\begin{array}{c}\text { Fuera } \\
\text { España }\end{array}$ \\
Totalmente en desacuerdo & 3.0 & $3.9+$ & $1.8-$ & $2,5-$ & 3,1 & $4,9+$ \\
En desacuerdo & 2.5 & $3.8+$ & $1,0-$ & 2,3 & 3,1 & 2,7 \\
Ni de acuerdo, ni en & 12.4 & $17.7+$ & $6.9-$ & 12,0 & 6,3 & 14.6 \\
desacuerdo & & & & & & \\
De acuerdo & 31.1 & $36.1+$ & $26,0-$ & 30,8 & 34,4 & 31,7 \\
Totalmente de acuerdo & 48.5 & $36.0-$ & $62.0-$ & $50,3+$ & 53,1 & $42,3-$ \\
Ns/Nc & 2.5 & 2.6 & 2.4 & 2,2 & - & 3,8 \\
\hline
\end{tabular}

El primer supuesto dado hace referencia al reparto de las tareas del hogar (Tabla 13). Cabe señalar que, sumados los dos ítems de valoración más alta "De acuerdo" y "Totalmente de acuerdo", en las respuestas globales llegan al 79,6\% del total. El análisis parcial ofrece datos más relevantes aun. Analizadas las respuestas según el lugar de origen de los adolescentes, los porcentajes que destacan corresponden a las respuestas en los dos extremos de la escala de los nacidos en el extranjero. Mientras que las respuestas del resto de grupos rozan el 3\%, en su caso superan este índice ampliamente en dos puntos llegando al 5\%. A su vez, el porcentaje del ítem "totalmente de acuerdo" es el más bajo de todos los grupos con un $42,3 \%$ que tiene significación estadística. Sumado este con el porcentaje de los que están "de acuerdo" alcanza el 74\% que aunque es alto está muy por debajo del $87,5 \%$ del grupo de origen español y del $80 \%$ de los nacidos en Cataluña.

También se les planteó situaciones sobre tópicos relacionados con el éxito escolar y las oportunidades educativas. Los resultados están sintetizados en las tablas 14 y 15 . En el supuesto de si en una familia numerosa que no pudieran estudiar todos los hijos, deberían ser ellos y no ellas las que tuvieran prioridad, las respuestas siguen tendencias similares a los casos anteriores (Tabla 14). Comparados los datos de ellos y ellas se observa que el porcentaje de los que se sitúan en el ítem de ambigüedad duplica ampliamente el de ellas: el $17,1 \%$ frente al $8,5 \%$ respectivamente. Igualmente, no llegan a la mitad $(47,6 \%)$ los que no están en absoluto de 


\section{Sanvicén, Fuentes \& Molina-Alteridad e Interculturalidad}

acuerdo con la diferenciación de oportunidad por razón de sexo, frente al $70,4 \%$ de las respuestas de las chicas. Observados los datos en función del origen, se observa que no llega a la mitad del grupo los nacidos en el extranjero que se manifiestan contra la decisión propuesta en la pregunta, siendo el valor más bajo del resto. En ese ítem el valor significativamente más alto es el de los nacidos en Cataluña con el 61,0\% de los resultados.

Tabla 14

En una familia numerosa, se debería incitar más a los chicos que vayan a la universidad que a las chicas. Variables sexo y lugar de nacimiento (\%)

\begin{tabular}{lcccccc}
\hline Respuesta & Total & Chico & Chica & Cataluña & $\begin{array}{c}\text { Resto } \\
\text { España }\end{array}$ & Fuera España \\
\hline $\begin{array}{l}\text { Totalmente en } \\
\text { desacuerdo }\end{array}$ & 58,6 & $47,6-$ & $70,4+$ & $61,0+$ & 59,4 & $49,9-$ \\
En desacuerdo & 21,4 & $27,1+$ & $15,3-$ & 20,8 & 15,6 & 24.1 \\
Ni de acuerdo, & 12,9 & $17,1+$ & $8,5-$ & 12,2 & 12,5 & 15,7 \\
ni en desacuerdo & & & & & & \\
De acuerdo & 3,1 & 3,8 & 2,3 & $2,4-$ & 3,1 & $5,4+$ \\
$\begin{array}{l}\text { Totalmente de } \\
\text { acuerdo }\end{array}$ & 1,4 & 1,7 & 1,1 & 1,2 & 9,4 & 1,4 \\
Ns/Nc & 2,6 & 2,7 & 2,4 & 2,4 & - & 3,5 \\
\hline
\end{tabular}

Sobre si es más importante que un chico tenga más éxito escolar que las chicas, aunque se mantienen las tendencias entre grupos y variables, las cifras del desacuerdo son superiores en comparación con el supuesto anterior (Tabla 15). Del amplio 83,4\% del total acumulado en el nivel de desacuerdo más rotundo, destaca una vez más la distancia entre el volumen de respuesta de ellos 51,0\% y el de ellas 77,9\%. El índice de desacuerdo de los nacidos en Cataluña, aunque superado por los nacidos en el resto de España, es estadísticamente significativo (66,2\%), y también lo es el del grupo de nacidos fuera de España que también en este caso alcanza el menor porcentaje en comparación con los demás. 


\section{Tabla 15}

Es más importante que los chicos tengan más éxito en la escuela que las chicas.

\begin{tabular}{|c|c|c|c|c|c|c|}
\hline Respuesta & Total & Chico & Chica & Cataluña & $\begin{array}{l}\text { Resto } \\
\text { España }\end{array}$ & Fuera España \\
\hline $\begin{array}{l}\text { Totalmente en } \\
\text { desacuerdo }\end{array}$ & 64,0 & $51,0-$ & $77,9+$ & $66,2+$ & 68,8 & $55,8-$ \\
\hline En desacuerdo & 19,4 & $26,8+$ & $11,6-$ & 18,8 & 18,8 & 21,4 \\
\hline $\begin{array}{l}\text { Ni de acuerdo, } \\
\text { ni en } \\
\text { desacuerdo }\end{array}$ & 10,5 & $14,5+$ & $6,2-$ & 9,8 & 9,4 & 12,7 \\
\hline De acuerdo & 2,5 & $3,4+$ & $1,2-$ & $1,9-$ & 3,1 & $4,3+$ \\
\hline $\begin{array}{l}\text { Totalmente de } \\
\text { acuerdo }\end{array}$ & 0,7 & $1,3-$ & $0,1-$ & 0,6 & - & 1,1 \\
\hline $\mathrm{Ns} / \mathrm{Nc}$ & 3,0 & 3,1 & 3,0 & 2,7 & - & 4,6 \\
\hline
\end{tabular}

También se les plantearon cuestiones referentes a los roles tradicionales de mujer-madre-esposa y los roles de autoridad paternos (Tabla 16 y 17). No llega al $10 \%$ el número de chicas que eligen la ambigüedad en el supuesto que el padre debe ser quien toma las decisiones y solo el 2,9\% suscriben esa idea. Esos datos contrastan significativamente con el 19,4\% y el 6,0\% de las respuestas de ellos.

Tabla 16

Las chicas deberían preocuparse más de ser buenas esposas y madres que de tener una profesión. Variables sexo y lugar de nacimiento. (\%)

\begin{tabular}{lcccccc}
\hline Respuesta & Total & Chico & Chica & Cataluña & $\begin{array}{c}\text { Resto } \\
\text { España }\end{array}$ & $\begin{array}{c}\text { Fuera } \\
\text { España }\end{array}$ \\
\hline $\begin{array}{l}\text { Totalmente en } \\
\text { desacuerdo }\end{array}$ & 64,5 & $52,7-$ & $77,2+$ & $68,0+$ & 71,9 & $51,5-$ \\
$\begin{array}{l}\text { En desacuerdo } \\
\text { Ni de acuerdo, ni } \\
\text { en desacuerdo }\end{array}$ & 15,9 & $22,6+$ & $8,8-$ & 15,3 & 6,3 & 19,0 \\
$\begin{array}{l}\text { De acuerdo } \\
\begin{array}{l}\text { Totalmente de } \\
\text { acuerdo }\end{array}\end{array}$ & $14,8+$ & $8,1-$ & $10,2-$ & 12,5 & $16,3+$ \\
Ns/Nc & 2,4 & $3,7+$ & $1,6-$ & $1,7-$ & 6,3 & $4,6+$ \\
\hline & 2,5 & 2,8 & 2,2 & 2,3 & - & 3,5 \\
\hline
\end{tabular}




\section{Sanvicén, Fuentes \& Molina-Alteridad e Interculturalidad}

En el extremo opuesto, continúa observándose claras diferencias: el $71,1 \%$ de ellas están totalmente en desacuerdo con esa creencia mientras que ellos no llegan al 50\%, solo lo está el 43,8\%. Por origen, cerca de un $70 \%$ de los nacidos fuera de España se manifiestan favorables a la igualdad, aunque hay un significativo 7,0\% que está de acuerdo. Con todo, sumados los ítems, los que se manifiestan más favorables a la autoridad paterna sobre la materna son los nacidos en el resto de España que alcanza un relevante 12, $6 \%$.

Tabla 17

En general, el padre debería tener más autoridad que la madre a la hora de tomar decisiones que afectan la familia. Variables sexo y lugar de nacimiento \%

\begin{tabular}{lcccccc}
\hline Respuesta & Total & Chico & Chica & Cataluña & $\begin{array}{c}\text { Resto } \\
\text { España }\end{array}$ & $\begin{array}{c}\text { Fuera } \\
\text { España }\end{array}$ \\
\hline $\begin{array}{l}\text { Totalmente en } \\
\text { desacuerdo }\end{array}$ & 57,0 & $43,8-$ & $71,1+$ & $61,1+$ & 62,5 & $42,0-$ \\
$\begin{array}{l}\text { En desacuerdo } \\
\text { Ni de acuerdo, ni en } \\
\text { desacuerdo }\end{array}$ & 19,3 & $24,4+$ & $14,0-$ & 17,9 & 9,4 & $24,9+$ \\
$\begin{array}{l}\text { De acuerdo } \\
\text { Totalmente de }\end{array}$ & 14,7 & $19,4+$ & $9,7-$ & $13,2-$ & 15,6 & $19,8+$ \\
acuerdo & 1,6 & $6,9+$ & $1,8-$ & $3,8+$ & 6,3 & $7,0+$ \\
Ns/Nc & $2,7+$ & $1,1-$ & 1,6 & 6,3 & 2,7 \\
& 2,5 & 2,7 & 2,3 & 2,3 & - & 3,5 \\
\hline
\end{tabular}

También se les planteó un supuesto que como adolescentes pueden haber protagonizado, que tiene que ver con el carácter pasivo atribuido a las chicas en las relaciones amorosas (Tabla 18). Es relevante señalar que, de todas las preguntas de este tipo, es la que alcanza la mayor igualdad porcentual en las respuestas entre chicos y chicas, hasta casi un empate. Sumados los dos ítems de mas acuerdo de la escala (de acuerdo/totalmente de acuerdo) resulta un $81,1 \%$ de respuestas de las chicas y un $81,0 \%$ en los chicos. El grado de significación estadística aparece en la variable origen. Ninguno de los nacidos en España se sitúa en los ítems de desacuerdo. Del grupo de los nacidos fuera, el 11,9\% manifiesta una actitud de desacuerdo sumando los dos ítems que recogen esa opción. A su vez, el 20,9\% se sitúa en la opción ambigua, a una distancia considerable respecto el resto de grupos. 
Tabla 18

No pasa nada si es la chica la que le pide al chico que salga con ella. Variables sexo y lugar de nacimiento (\%)

\begin{tabular}{lcccccc}
\hline Respuesta & Total & Chico & Chica & Cataluña & $\begin{array}{c}\text { Resto } \\
\text { España }\end{array}$ & Fuera España \\
\hline $\begin{array}{l}\text { Totalmente } \\
\text { en }\end{array}$ & 2,1 & 1,7 & 2,5 & $1,5-$ & - & $4,6+$ \\
desacuerdo & 2,9 & 3,0 & 2,7 & $1,7-$ & - & $7,3+$ \\
$\begin{array}{l}\text { En } \\
\text { desacuerdo }\end{array}$ & 11,4 & 11,4 & 11,5 & $8,7-$ & 15,6 & $20,9+$ \\
$\begin{array}{l}\text { Ni de } \\
\text { acuerdo, ni en } \\
\text { desacuerdo }\end{array}$ & & & & & & \\
$\begin{array}{l}\text { De acuerdo } \\
\begin{array}{l}\text { Totalmente } \\
\text { de acuerdo }\end{array}\end{array}$ & 56,1 & 24,3 & 25,5 & 24,4 & 28,1 & 26,0 \\
Ns/Nc & 2,6 & 3,0 & 2,3 & 2,5 & - & $37,7-$ \\
\hline
\end{tabular}

El resumen de las cifras globales permite completar el análisis de detalle anterior. La tabla que recoge los tres grados de acuerdo de la escala (Tabla 19) refleja que incluso los supuestos que han obtenido un porcentaje más rotundo a favor de la igualdad de género, se sitúan solo alrededor del $80 \%$. En general, con los matices que ya se han comentado anteriormente, no deja de sorprender que entrado el siglo XXI, aun haya entre un 20-30\% de adolescentes que subscriben de alguna manera los supuestos estereotipados de diferenciación de rol por razón de género. Los resultados muestran una vez más la evidencia que la educación de género es una tarea urgente dentro y fuera de las aulas infantiles y juveniles. (Martín \& Tellado, 2012; Nash, 2006; Subirats et alt., 2013). 


\section{Sanvicén, Fuentes \& Molina-Alteridad e Interculturalidad}

Tabla 19

Total de resultados Género por grados de acuerdo según la escala. (\%)

\begin{tabular}{|c|c|c|c|}
\hline Respuesta & $\begin{array}{l}\text { Desacuerdo } \\
\text { (suma } \\
\text { Totalmente } \\
\text { desacuerdo+ } \\
\text { En } \\
\text { desacuerdo) }\end{array}$ & $\begin{array}{l}\text { Acuerdo } \\
\text { (suma } \\
\text { De acuerdo+ } \\
\text { Totalmente } \\
\text { acuerdo) }\end{array}$ & $\begin{array}{l}\text { Ambigüedad } \\
(\mathrm{Ni} \text { de } \\
\text { acuerdo/ ni en } \\
\text { desacuerdo) }\end{array}$ \\
\hline $\begin{array}{l}\text { No pasa nada si es la chica la que le pide al } \\
\text { chico que salga con ella }\end{array}$ & 5,0 & 80,1 & 11,4 \\
\hline $\begin{array}{l}\text { Si en una casa tanto el hombre como la mujer } \\
\text { trabajan fuera de casa, el hombre debería } \\
\text { participar en las tareas del hogar }\end{array}$ & 5,5 & 79,6 & 12,4 \\
\hline $\begin{array}{l}\text { Es más importante que los chicos tengan más } \\
\text { éxito en la escuela que las chicas }\end{array}$ & 73,4 & 3,2 & 10,5 \\
\hline $\begin{array}{l}\text { En general, el padre debería tener más } \\
\text { autoridad que la madre a la hora de tomar } \\
\text { decisiones que afectan la familia }\end{array}$ & 75,3 & 6,5 & 14,7 \\
\hline $\begin{array}{l}\text { En una familia numerosa, se debería incitar } \\
\text { más a los chicos que vayan a la universidad } \\
\text { que a las chicas }\end{array}$ & 80,0 & 4,5 & 12,9 \\
\hline $\begin{array}{l}\text { Las chicas deberían preocuparse más de ser } \\
\text { buenas esposas y madres que de tener una } \\
\text { profesión }\end{array}$ & 80,4 & 5,4 & 11,6 \\
\hline
\end{tabular}

\section{El Entorno y la Frecuencia de las Relaciones con los Otros, Factores a Tener en Cuenta}

Una de las hipótesis manejadas es que el entorno y las experiencias propias son elementos que determinan la actitud de los individuos respecto la alteridad. En ese sentido es relevante conocer la frecuencia de las relaciones con personas diferentes. Las variables que se han tenido en cuenta para describir la diferencia en este caso son la nacionalidad, la ideología política, la lengua, la religión y la edad. Los resultados están representados gráficamente en las tablas 21 a 24. En líneas generales, cabe señalar que se comprueba que, en todos los casos, se mantiene la tendencia ya observada de una mayor permeabilidad manifestadas por las chicas. 
Tabla 20

Bloque 18

Bloque 18. Pregunta 2 Con qué frecuencias te relacionas con gente....

Marca la casilla de cada fila que mejor se ajuste a tu situación: Nunca; Poco; De tanto en tanto; A menudo; Muy a menudo.

- ... De otras nacionalidades

- De otras ideologías políticas.

- Que habla una lengua o lenguas en casa diferentes a la mía/mías

- De otras religiones

- De otras edades

Sobre la habitualidad de sus relaciones con personas de nacionalidades, ideologías, lenguas, religiones y edades diferentes, los datos muestran que la ideología política (tabla 22) y la religión (tabla 24) son los dos factores que concentran el mayor porcentaje de rechazo. Comparativamente, la política concentra aun un porcentaje mayor del "no relacionarse nunca" con un $8,8 \%$ frente al 7,3\% de los que nunca tratan con otros creyentes. En la medida que no tiene marca subjetiva de ningún tipo, en general la edad es la variable con la que dicen relacionarse más frecuentemente, con todo destaca el casi $10 \%$ de los nacidos fuera de España que indican poca relación. En el caso de las lenguas, tiene interés reseñar el mas del 15\% de los nacidos en España que manifiestan no hablar nunca con otros hablantes. En ese mismo aspecto, continúa destacando la diferencia entre chicos y chicas, siendo ellas las que manifiestan relacionarse más frecuentemente con personas de lenguas diferentes que ellos. 
50 Sanvicén, Fuentes \& Molina-Alteridad e Interculturalidad

Tabla 21

Frecuencia de relación con personas de otras nacionalidades. Variables sexo y lugar de nacimiento (\%)

\begin{tabular}{lcccccc}
\hline Respuesta & Total & Chico & Chica & Cataluña & $\begin{array}{c}\text { Resto } \\
\text { España }\end{array}$ & $\begin{array}{c}\text { Fuera } \\
\text { España }\end{array}$ \\
\hline Nunca & 3,6 & 3,5 & 3,4 & 3,9 & 3,1 & 2,4 \\
Poco & 15,3 & 15,6 & 15,1 & $16,9+$ & 12,5 & $10,3-$ \\
$\begin{array}{l}\text { De vez en } \\
\text { cuando }\end{array}$ & 27,6 & 26,7 & 28,5 & $29,8+$ & 37,5 & $18,4-$ \\
A menudo & 30,1 & 31,4 & 28,9 & 30,4 & 21,9 & 30,1 \\
Muy a menudo & 21,7 & 20,6 & 22,9 & $17,3-$ & 25,0 & $36,9+$ \\
Ns/nc & 1,7 & 2,2 & 1,2 & 1,7 & - & 1,9 \\
\hline
\end{tabular}

Tabla 22

Frecuencia de relación con personas de otras ideologías políticas. Variables sexo y lugar de nacimiento (\%)

\begin{tabular}{lcccccc}
\hline Respuesta & Total & Chico & Chica & Cataluña & $\begin{array}{c}\text { Resto } \\
\text { España }\end{array}$ & $\begin{array}{c}\text { Fuera } \\
\text { España }\end{array}$ \\
\hline Nunca & 8,8 & 8,1 & 9,5 & $7,2-$ & 12,5 & $13,8+$ \\
Poco & 16,4 & 16,5 & 16,3 & $14,6-$ & 15,6 & $23,0+$ \\
De vez en cuando & 27,7 & 27,9 & 27,5 & 27,7 & 31,3 & 27,9 \\
A menudo & 29,2 & 30,3 & 28,0 & $31,9+$ & 18,8 & $20,3-$ \\
Muy a menudo & 14,6 & 13,7 & 15,6 & 15,3 & 21,9 & $11,4-$ \\
Ns/nc & 3,3 & 3,5 & 3,0 & 3,3 & - & 3,5 \\
\hline
\end{tabular}

Tabla 23

Frecuencia de relación con personas que hablan lenguas diferentes. Variables sexo y lugar de nacimiento (\%)

\begin{tabular}{lcccccc}
\hline Respuesta & Total & Chico & Chica & Cataluña & $\begin{array}{c}\text { Resto } \\
\text { España }\end{array}$ & $\begin{array}{c}\text { Fuera } \\
\text { España }\end{array}$ \\
\hline Nunca & 4,7 & $5,9+$ & $3,5-$ & 4,7 & 15,6 & 3,8 \\
Poco & 12,9 & 12,2 & 13,6 & 12,3 & 18,8 & 14,9 \\
De vez en cuando & 23,0 & 24,7 & 21,0 & 23,7 & 18,8 & 20,9 \\
A menudo & 31,9 & 32,8 & 31,2 & 33,0 & 21,9 & 29,0 \\
Muy a menudo & 25,4 & $21,9-$ & $29,2+$ & 24,5 & 25,0 & 28,7 \\
Ns/nc & 2,0 & 2,5 & 1,4 & 1,8 & - & 2,7 \\
\hline
\end{tabular}


Tabla 24

Frecuencia de relación con personas que profesan una religión diferente. Variables sexo y lugar de nacimiento $(\%)$

\begin{tabular}{llllllc}
\hline Respuesta & Total & Chico & Chica & Cataluña & $\begin{array}{c}\text { Resto } \\
\text { España }\end{array}$ & $\begin{array}{c}\text { Fuera } \\
\text { España }\end{array}$ \\
\hline Nunca & 7,3 & 8,2 & 6,3 & 7,7 & 6,3 & 6,0 \\
Poco & 20,1 & 21,0 & 19,3 & $21,6+$ & 12,5 & $15,4-$ \\
De vez en & 26,3 & 26,4 & 26,1 & 26,1 & $43,8+$ & 25,5 \\
cuando & & & & & & \\
A menudo & 28,7 & 28,1 & 29,1 & 29,0 & 18,8 & 28,5 \\
Muy a menudo & 15,5 & 14,0 & 17,1 & $13,4-$ & 15,6 & $22,8+$ \\
Ns/nc & 2,2 & 2,3 & 2,1 & 2,2 & 3,1 & 1,9 \\
\hline
\end{tabular}

Tabla 25

Frecuencia de relación con personas de otras edades. Variables sexo y lugar de nacimiento (\%)

\begin{tabular}{lcccccc}
\hline Respuesta & Total & Chico & Chica & Cataluña & $\begin{array}{c}\text { Resto } \\
\text { España }\end{array}$ & $\begin{array}{c}\text { Fuera } \\
\text { España }\end{array}$ \\
\hline Nunca & 0,9 & 1,0 & 0,8 & 0,7 & 3,1 & 1,6 \\
Poco & 4,9 & $6,4+$ & $3,3-$ & $3,5-$ & 3,1 & $9,8+$ \\
De vez en & 15,0 & 16,2 & 13,6 & 14,4 & 12,5 & 17,1 \\
cuando & & & & & & \\
A menudo & 34,3 & 36,0 & 32,6 & 35,2 & 25,0 & 31,7 \\
Muy a menudo & 42,9 & $37,9-$ & $48,1+$ & 44,1 & 56,3 & $37,7-$ \\
Ns/nc & 2,0 & 2,5 & 1,6 & 2,1 & - & 2,2 \\
\hline
\end{tabular}

Una vez constatadas los datos sobre la frecuencia de las relaciones, interesaba saber dónde tienen lugar esas relaciones (pregunta 3. Bloque 18). Las preguntas en este apartado eran de respuesta múltiple, por tanto los resultados reflejan diferentes ámbitos relacionales. Así, los datos globales, sintetizados en la tabla 26, muestran que hay tres espacios de encuentro de los adolescentes con sus entornos de heterogeneidad que son, por este orden, el centro educativo, el barrio y el espacio virtual. Por su interés, dedicamos un apartado específico a tratar los datos relativos al espacio virtual. Le 


\section{Sanvicén, Fuentes \& Molina - Alteridad e Interculturalidad}

siguen, a una distancia considerable, los espacios que proporcionan las actividades extraescolares y en último término, de manera significativa, el hogar familiar. Aunque no lo es a efectos estadísticos, otorgamos el carácter de relevancia a este dato en nuestro estudio porque en la pregunta se explicitaba con claridad el hogar como "mi casa o la del otro/a." Los resultados evidencian que, cuando la hay, la interacción con personas diferentes se da en espacios alejados de las normas del hogar familiar.

Tabla 26

Datos globales respecto a los espacios en los que se relacionan con otras personas

\begin{tabular}{lccccc}
\hline $\begin{array}{l}\text { Espacio de } \\
\text { relación }\end{array}$ & $\begin{array}{c}\text { otras } \\
\text { nacionalidades }\end{array}$ & $\begin{array}{c}\text { otras } \\
\text { ideologías }\end{array}$ & otras lenguas & $\begin{array}{c}\text { otras } \\
\text { religiones }\end{array}$ & otras edades \\
\hline Colegio & 63,7 & 54,8 & 58,0 & 59,7 & 53,0 \\
Barrio & 32,5 & 25,7 & 34,5 & 30,8 & 57,3 \\
Hogar & 10,0 & 13,8 & 15,6 & 8,8 & 36,3 \\
Internet & 34,6 & 17,6 & 37,0 & 21,5 & 45,8 \\
Actividades & 22,1 & 14,6 & 21,7 & 15,7 & 37,1 \\
$\begin{array}{l}\text { extraescol. } \\
\text { No hay }\end{array}$ & 3,7 & 16,9 & 5,4 & 12,0 & 2,1 \\
relación & 2,3 & 4,7 & 2,8 & 3,3 & 2,9 \\
Ns/nc & & & & & \\
\hline
\end{tabular}

Igualmente, es interesante señalar la existencia de datos estadísticamente significativos entre los que manifiestan que solo se relacionan con sus iguales y se mantienen refractarios a las diferencias. En ese sentido, cabe destacar el alto grado de significación del 16,9\% de adolescentes que no interaccionan con otras ideologías. Analizados las respuestas, se observa que, en este caso, las chicas se relacionan aun tres puntos porcentuales menos que los chicos, un 18,8\% (+) respecto el 15,0\% (-). Igualmente es significativa la variable origen ya que la ausencia de relación es apuntada por el 26,0\% (+) de los nacidos fuera de España y el 14,4\% (-) de los nacidos en Cataluña. En ese sentido, los nacidos en España son los que más manifiestan relacionarse con personas de ideología diferente a la suya, ya que solo un $12,5 \%$ manifiesta que no lo hace. Respecto a este último dato, es interesante observar que ese mismo $12,5 \%$ se repite también en el caso de la no relación con personas de lenguas y religiones diferentes. 


\section{La Red, un Potente Espacio de Influencia, Aunque no el Más Relevante}

Otro de los ejes que nos ayudan a dibujar la red de relaciones que establecen los adolescentes es internet. La rápida entrada de la red en los hogares en la última década y especialmente la masiva habituación al uso del móvil y las redes sociales cada vez a edades más tempranas, ha motivado que el estudio sobre su influencia en la generación joven y adolescente centralice buena parte de los intereses científicos, especialmente de pedagogos y sociólogos. (Caceres et al., 2009; Colás et al., 2013; García, 2013; Espuny et al., 2010; Imbert, 2011; Pantoja et al., 2012)

Para ello se gestaron una serie de cuestiones sobre el uso de las tecnologías de la información. Éstas quedan recogidas de forma introductoria en el Bloque 1 preguntas 14 y 15 sobre la disponibilidad de Internet en casa; motivos por los que utilizas internet y frecuencias de conexión.

Los adolescentes encuestados en este estudio forman parte de la generación que ya se está socializando y creando su opinión sobre el mundo que le rodea a través de la información que recibe directamente. Preguntados por la frecuencia de conexión diaria a través del móvil, las respuestas reflejan diversas cifras estadísticamente significativas. Una de ellas es la que hace referencia a la disponibilidad que tienen de usar Internet en sus casas.

Tabla 27

Disponibilidad de Internet en casa. Variables sexo y lugar de origen (\%)

\begin{tabular}{lcccccc}
\hline Respuesta & Total & Chico & Chica & Cataluña & $\begin{array}{c}\text { Resto } \\
\text { España }\end{array}$ & $\begin{array}{l}\text { Fuera } \\
\text { España }\end{array}$ \\
\hline Sí & 92,2 & 92,9 & 91,4 & $93,2+$ & 90,6 & $88,6-$ \\
No & 7,5 & 7,1 & 8,6 & $6,8-$ & 9,4 & $11,4+$ \\
\hline
\end{tabular}

Como queda sintetizado en la tabla 27, aunque los hogares de los encuestados disponen de conexión a la red de manera mayoritaria, el 92,3\%, no es menor el dato que un 7,5\% manifiesta que no tiene esa disponibilidad. En estudios anteriores, referidos a estudiantes de primer curso universitario, ya se ha señalado ese hecho como un elemento a tener en cuenta que indica una cierta desigualdad respecto al acceso a recursos en una sociedad 


\section{Sanvicén, Fuentes \& Molina - Alteridad e Interculturalidad}

mediatizada por la red. ${ }^{4}$ Puestos los datos en relación con el sexo y el origen, se observan dos grupos significativos, por un lado los datos de los nacidos en Cataluña que se sitúan por encima de la media siendo con el 93,2\% el valor más alto de la variable, efecto que sigue el resultado de los que manifiestan no tener acceso en el hogar, que son un 6,8\%. Igualmente cabe señalar que el grupo que manifiesta tener menor disponibilidad es el de origen extranjero. A su vez, ese grupo concentra el mayor porcentaje de los adolescentes que manifiestan no tener Internet en casa que llega al 11,4\%.

Tabla 28

Frecuencia de conexión a Internet con móvil/Smartphone. Variables sexo y lugar de nacimiento (\%)

\begin{tabular}{lcccccc}
\hline Respuesta & Total & Chico & Chica & Cataluña & $\begin{array}{c}\text { Resto } \\
\text { España }\end{array}$ & $\begin{array}{c}\text { Fuera } \\
\text { España }\end{array}$ \\
\hline $\begin{array}{l}\text { Más de una vez al } \\
\text { mes }\end{array}$ & 1,3 & 1,1 & 1,2 & $0,8-$ & 3,1 & 2,4 \\
$\begin{array}{l}\text { Más de una vez a } \\
\text { la semana } \\
\text { Más de una vez al }\end{array}$ & 2,1 & $3,1+$ & $1,1-$ & 1,9 & 6,3 & 2,4 \\
día & 5,1 & $6,4+$ & $3,9-$ & 4,6 & 3,1 & $7,3+$ \\
$\begin{array}{l}\text { Entre 1 y 5 veces } \\
\text { al día }\end{array}$ & 17,1 & $19,4+$ & $14,9-$ & $18,4+$ & 6,3 & 13,8 \\
$\begin{array}{l}\text { Más de 5 veces al } \\
\text { día }\end{array}$ & 64,5 & $59,9-$ & $69,4+$ & 65,7 & 68,8 & $59,9-$ \\
Nunca & 7,0 & 6,7 & 7,2 & 6,4 & 9,4 & 7,6 \\
Ns/nc & 2,9 & 3,4 & 2,3 & $2,2-$ & 3,1 & $5,1+$ \\
\hline
\end{tabular}

Aun así, la utilización de móvil es generalizada y los espacios de conexión con wifi libre son diversos. Eso explica que, tal como queda reflejado en la tabla 28, los datos de frecuencia muestran que no se llega en ningún caso al $10 \%$ de adolescentes que manifiestan que no se conectan nunca a través del móvil.

El porcentaje mayoritario se concentra en el índice de más alta actividad. El $64,5 \%$ de los encuestados manifiestan conectarse más de cinco veces al día. En ese nivel, las chicas superan en 10 puntos porcentuales a los chicos, 
datos estadísticamente significativos. El grupo que manifiesta un uso menor en esa franja de frecuencia es, también significativamente, el de nacidos en el extranjero que se sitúa por debajo del $60 \%$.

Estos datos guardan relación con los recogidos en la tabla 26 ya comentada anteriormente. Se han analizado específicamente los datos referidos al espacio virtual de relación para detectar los resultados estadísticamente significativos. Como se observa en la síntesis de la Tabla 27, en general las relaciones en la red son mayoritariamente con personas de edades, lenguas y nacionalidades diferentes. Son significativos los datos referidos al comportamiento de chicos y chicas respecto a nacionalidades, ideologías y edades. Mientras que las chicas superan en cinco puntos porcentuales a los chicos tanto en relacionarse con personas de otras edades y otras nacionalidades, ellos las superan casi en igual cantidad en el ámbito de las ideologías. Esta diferencia en particular guarda relación con otros resultados recogidos en la propia investigación que muestran un menor interés de las adolescentes encuestadas respecto de los chicos por la política. Analizados los resultados según el origen, cabe señalar el 38’3\% de adolescentes catalanes de origen que manifiestan buscar personas de otras lenguas, dato relevante por el momento en que se realizó la encuesta en el inicio del auge independentista catalán. Igualmente significativo es el escaso $15,6 \%$ de los nacidos en el resto de España, hecho que probablemente denota una cierta actitud respecto el ambiente de polarización creado. Así mismo tiene interés la falta absoluta de respuesta de los nacidos fuera de España en el ídem "otras religiones" y el $26,6 \%$ con valor estadístico de los nacidos en el extranjero, colectivos, como es sabido, de prácticas religiosas diversas. 


\section{Sanvicén, Fuentes \& Molina-Alteridad e Interculturalidad}

Tabla 29

Internet como espacio de relación con personas diferentes. Variables sexo y origen (\% verticales)

\begin{tabular}{lcccccc}
\hline $\begin{array}{l}\text { Relaciones en } \\
\text { Internet } \begin{array}{c}\text { con } \\
\text { personas de... }\end{array}\end{array}$ & Total & Chico & Chica & Cataluña & $\begin{array}{l}\text { Resto de } \\
\text { España }\end{array}$ & $\begin{array}{l}\text { Fuera de } \\
\text { España }\end{array}$ \\
\hline $\begin{array}{l}\text { Otras } \\
\text { nacionalidades }\end{array}$ & 34,6 & $32,2-$ & $37,3+$ & 34,1 & 21,9 & 17,9 \\
$\begin{array}{l}\text { Otras } \\
\text { ideologías }\end{array}$ & 17,6 & $19,9+$ & $15,1-$ & 17,5 & 6,3 & 18,7 \\
$\begin{array}{l}\text { Otras lenguas } \\
\begin{array}{l}\text { Otras } \\
\text { religiones }\end{array}\end{array}$ & 37,0 & 35,3 & 38,9 & $38,3+$ & $15,6-$ & 34,4 \\
Otras edades & 45,8 & 20,7 & 22,3 & 20,7 & - & $26,6+$ \\
\hline
\end{tabular}

Los adolescentes encuestados manifiestan que el espacio virtual es uno de sus tres principales espacios en los que se relacionan con personas diferentes a ellos. Es importante destacar el hecho que la red aparezca en tercer lugar. Influenciados por la vida cotidiana en la que la red forma parte ineludible en todos los ámbitos, la intuición preliminar esperada era que los adolescentes lo situaran en el primer lugar. No ha sido así y significativamente el entorno escolar y el barrio, espacios de relación y contacto físico, son aun los predominantes.

\section{Conclusiones}

Teniendo en cuenta los resultados de nuestra investigación se puede afirmar que las reflexiones que se derivan referidas al objetivo inicial son ciertamente muy interesantes y atractivas.

En este sentido y en primer lugar, considerando los resultados expuestos, puede afirmarse que los estudiantes analizados se muestran proclives a la heterogeneidad, mostrando porcentajes elevados de respuestas de interés medio (ni acuerdo ni desacuerdo) cuando se refieren a afirmaciones sobre si les gusta trabajar en grupo con personas de diferentes procedencias; si pueden aprender de personas que vienen de fuera de nuestro país o la importancia de escuchar las ideas de los otros aunque sean muy diferentes a las nuestras. Así, cabe señalar que las mujeres muestran una actitud más favorable a la heterogeneidad, advirtiéndose porcentajes más altos de respuestas de interés alto (de acuerdo/muy de acuerdo) con definiciones 
proclives a considerar la multiculturalidad como un valor positivo. Dicha tendencia se mantiene constante en todos los casos.

La excepción que merece ser considerada es la referida a la religión y la política. Cuando los adolescentes son instados a reflexionar sobre si conocer personas que tienen creencias religiosas o políticas diferentes puede ser interesante y beneficioso para sus vidas, los resultados suelen mostrar más dudas al respecto y porcentajes de desacuerdo más altos, especialmente en los chicos, ya que las chicas continúan mostrándose más proclives.

Otra de las variables de selección que nos interesaba testar era el lugar de nacimiento/procedencia familiar. En este sentido, los resultados indican que haber nacido o proceder de una familia autóctona no implica tener una actitud más favorable sobre la alteridad. En este sentido, se advierte que el conocimiento por parte de los adolescentes de las características culturales y normativas de los lugares de origen merece una atención especial. Este hecho se produce porque, aunque los estudiantes de otras procedencias ya viven y están socializados en nuestro país, el entorno familiar se constituye como el espacio donde se preservan dichas características diferenciadoras que los adultos desean mantener y transferir a los jóvenes. Resulta esencial el conocimiento y la comprensión de dichas realidades y valores, aspecto que debería generar enfoques curriculares de educación intercultural en los centros escolares de nuestro país, potenciando la capacidad crítica para poder relativizar, comparar, entender y valorar las distintas culturas.

Teniendo en cuenta las reflexiones sobre género y alteridad, se corrobora la necesidad de insistir y mejorar en la educación intercultural y la alteridad, de manera especialmente importante en la formación de los chicos, que se muestran más tajantes y con actitudes menos favorables que las chicas. Especialmente interesante advertir que todavía predominan actitudes que subscriben de alguna manera los supuestos estereotipados de diferenciación de rol por razón de género.

A la vez, nos interesaba averiguar cuáles eran los espacios de socialización, de contacto directo con personas de otras procedencias. En este sentido, se perfila la escuela y el barrio como los más relevantes, siendo las redes sociales contempladas, pero todavía minoritarias.

Así pues, resulta a todas luces evidente la necesidad que ya se comentaba anteriormente, de realizar un enfoque revolucionario del tratamiento de la interculturalidad y de la alteridad en los centros escolares. Por todo ello, 


\section{Sanvicén, Fuentes \& Molina - Alteridad e Interculturalidad}

consideramos necesario una renovación curricular que parta de la realidad de cada contexto educativo y que contemple de forma efectiva estos temas desde un prisma horizontal (ciclo) y vertical (colegial). De esta forma, se debería tratar de forma interdisciplinar en los proyectos competenciales propuestos y en la vida escolar reglada, para que pueda ser conocida e integrada en la vida de los estudiantes dentro de los centros.

Los datos del estudio muestran que es más necesario que nunca trabajar como objetivo didáctico y ciudadano la relación, el conocimiento y convivencia con los demás, cuanto más diferentes mejor, para potenciar una ciudadanía formada y cívica que difícilmente podrá construirse a través de la red, sin contacto personal.

\section{Notas}

1 Cabe citar también que forma parte del proyecto "Desarrollo de la información sociopolítica para una ciudadanía democrática: diseño e implementación de materiales didácticos en ciencias sociales" (EDU2015-65621-C3-3-R) financiado por el Ministerio de Economía y Competitividad del Gobierno de España.

2 Concretamente son tres preguntas del bloque 18 del cuestionario.

3 Bloque 1 pregunta 9. ¿En qué grupo te incluirías? Marca sólo una respuesta. A. No creo en dios, soy ateo. B. Creo en Dios pero no soy de ninguna religión; C. Soy católico; D. Soy musulmán; E. Soy cristiano protestante; F. Soy cristiano ortodoxo; G. Soy budista; H. Soy judío; I. Otras...

4 Se analiza ese aspecto en la investigación Estudio de las competencias digitales de los estudiantes de nuevo ingreso de la Udl-2016 financiado por los vicerrectorados de Docencia y Estudiantado. realizada por Montse Casanovas, Paquita Sanvicén, Yolanda Capdevila, Olivia Dumitrina y Jordi Bergé, miembros del Grup de recerca de Mediación Lingüística y del Grupo de Estudios en Sociedad, Salud, Educación y Cultura (GESEC), ambos de la Universitat de Lleida.

\section{Referencias}

Alcoverro, R., Alegret, L., Fernández, M. (2005) Pensar l'alteritat. Barcelona: La busca edicions

Cáceres, M. D.; Ruiz, S. R. y Brändle Señán, G. (2009). Comunicación interpersonal y vida cotidiana. La presentación de la identidad de los jóvenes en Internet, CIC. Cuadernos de Información y Comunicación, (14), 213-231 
Colás, P.; González, T. y de Pablos, J. (2013). Young People and Social Networks: Motivations and Preferred Uses, Comunicar, 20 (40), 15-23 http://dx.doi.org/10.3916/C402013-02-01

Deusdad, B. (2009) Immigrants a les escoles. Barcelona: Pagès Editors. Espuny, C.; Gisbert, M. y Coiduras, J. L. (2010). La dinamización de las TIC en las escuelas, Edutec: Revista electrónica de tecnología educativa, 32

Esquirol, M. (2005). Uno mismo y los otros: de las experiencias existenciales a la interculturalidad. Madrid: Herder.

Estruch, J. (2001). Les noves formes de religiositat. Barcelona: ed Cruïlla Estruch, J. (2007). Las otras religiones: minories religiosas en Catalunya, Barcelona: Icaria

García,A.; López de Ayala, M.C. y Catalina, B. (2013). Hábitos de uso en Internet y en las redes sociales de los adolescentes españoles, Comunicar, 21 (41), 195-204

Garreta, J. (2004). El espejismo cultural. La escuela de Catalunya ante la diversidad cultural. Revista de Educación, 333, 463480

Generalitat de Catalunya. (2013). Memòria del Departament d'Ensenyament 2013. Recuperado a partir de http://ensenyament.gencat.cat/ web/.content/home/departament/publicacions/memoriaactivitat-departament/memoria2013/text_complet_unic_document.pdf

Generalitat de Catalunya. (2014). Memòria del Departament d'Ensenyament 2014. Recuperado a partir de http://ensenyament.gencat.cat/ web/.content/home/departament/publicacions/memoria-activitatdepartament/memoria-2014/Text_complet_unic_document.pdf

Generalitat de Catalunya. (2014b). Baròmetre sobre la religiositat $i$ sobre la gestió de la seva diversitat.CEO. Recuperado a partir de http://governacio.gencat.cat/web/.content/afers_religiosos/documents /Mapa_2014/Barometre2014_resultats.pdf

Grande, I. \& Abascal, E. (2009). Fundamentos y técnicas de investigación comercial (10 a Edición). Madrid: ESIC Editorial. 
60 Sanvicén, Fuentes \& Molina - Alteridad e Interculturalidad

Imbert, G. (2011). La tribu informática: Identidades y máscaras en Internet, Revista de Estudios de Juventud, (92), 123-131

Jorba, R. (2011). La mirada del otro: manifiesto por la alteridad.

Barcelona: RBA Libros

Martín, N. \& Tellado, I. (2012). Violencia de Género y Resolución

Comunitaria de Conflictos en los Centros Educativos. Multidisciplinary Journal of Gender Studies, 1(3), 300-31 9. doi: 1 0.4471/generos.201 2.14 Recuperado de: http://dx.doi.org/1 $0.4471 /$ generos.201 2.14

Nash, M. (2006). Identidades de género, mecanismos de subalternidad y procesos de emancipación femenina. Revista CIDOB d'Afers Internacionals, 73-74, 39-57

Pantoja, A., Jiménez, A., Blanco, E. (2012). Diversidad cultural y redes sociales. Madrid: Joxman editores

Subirats, M.; Pérez, E.; Canales, A.; (2013). Género y educación, en Capitolina Díaz, Sociología y Género. Madrid: Tecnos, 201252

Villalobos , C.F; Álvarez , I.M; Vaquera, E. (2016) Amistades coétnicas e inter-étnicas en la adolescencia: diferencias en calidad, conflicto y resolución de problemas. Educación xxl, [s.1.], v. 20, n. 1, oct. 2016. Recuperado a partir de: http://revistas.uned.es/index.php/educacionxx1/article/view/1 7493

Paquita Sanvicén-Torné is Professor at the University of Lleida Spain.

Conxa Fuentes-Moreno is Professor at the University of Barcelona Spain.

Fidel Molina-Luque is Professor in at the University of Lleida, Spain.

Contact Address: psanvicen@geosoc.udl.cat 